\title{
Effect of Application of Remineralizing Agents on the Microhardness of Microabraded Teeth
}

\author{
${ }^{1}$ Zeeshan Hasanali Ladhani, ${ }^{2}$ Sayli Dargad, ${ }^{3}$ Vighnesh Dixit, ${ }^{4} S$ Srilatha, ${ }^{5}$ Vivek Hegde
}

\section{ABSTRACT}

Background: To evaluate microhardness of enamel surface after microabrasion of enamel using casein phosphopeptideamorphous calcium phosphate (CPP-ACP) and casein phosphopeptide-amorphous calcium phosphate with fluoride (CPP-ACPF).

\section{Materials and methods:}

- Ten freshly extracted anterior teeth were selected. Teeth were treated with abrasive slurry. This prepared slurry was applied to the labial aspects of teeth, using a rotating rubber cup, for 50 seconds. Each tooth was divided into four parts and treated accordingly with the topical application of the demineralizing agent stored in artificial saliva.

- The teeth were divided into four groups, as follows:

- Group A: Control group

- Group B: Microabrasion done but not treated

- Group C: Microabrasion done and CPP-ACP paste applied

- Group D: Microabrasion done and CPP-ACPF (i.e. with fluoride) applied.

- The microhardness was evaluated using the Vicker's microhardness test.

Results: Microhardness values were highest for the control group followed by group $D$, group $C$ and finally group $B$. Microabraded group of teeth with no topical application showed least microhardness values of all.

Conclusion: The CPP-ACPF increased the microabrasion significantly as compared to CPP-ACP and microabrasion group.

Keywords: CPP-ACP, CPP-ACPF, Microabrasion, Microhardness.

How to cite this article: Ladhani ZH, Dargad S, Dixit V, Srilatha S, Hegde V. Effect of Application of Remineralizing Agents on the Microhardness of Microabraded Teeth. World J Dent 2015;6(3):174-177.

Source of support: Nil

Conflict of interest: None

\footnotetext{
${ }^{1,2}$ Student, ${ }^{3-5}$ Professor

${ }^{1-5}$ Department of Conservative Dentistry and Endodontics, MA Rangoonwala College of Dental Sciences and Research Centre Pune, Maharashtra, India

Corresponding Author: Zeeshan Hasanali Ladhani, Student Department of Conservative Dentistry and Endodontics, MA Rangoonwala College of Dental Sciences and Research Centre Pune, Maharashtra, India, Phone: 9049445732, e-mail: zladhani@ gmail.com
}

\section{INTRODUCTION}

'The esthetic quality of a restoration may be as important to the mental health of the patient as the biological and technical qualities are to his physical or dental health' EW Skinner, 1959. In an increasingly esthetic driven world, attractive smiles may be marred by superficial stains or discolorations typically seen as isolated hypoplastic areas which may be yellow or white in color on an otherwise normal enamel surface. Such defects occur due to dental fluorosis and are emblematic of patients consuming drinking water with high fluoride content due to specific geographic pockets containing such quality of water.

A plethora of treatment options are now available to treat such discolorations, such as vital or non-vital bleaching, microabrasion, macroabrasion, and direct veneers or indirect veneers. Microabrasion may be used to treat isolated brown or white defects of a few tenths of a millimeter. ${ }^{1}$ Microabrasion has evolved from the use of $18 \%$ hydrochloric acid to remove superficial fluorosis stains ${ }^{2}$ to the incorporation of pumice and hydrochloric acid paste $^{3}$ to the replacement of pumice with silicon carbide particles. ${ }^{4}$ Today microabrasion may be performed by the application of an abrasive slurry comprising silicon carbide and hydrochloric acid assisted by a manual or handpiece driven rubbing action.

Enamel microabrasion not only helps remove superficial stains, but also improves surface texture and helps repair enamel decalcification and texture defects. ${ }^{5,6}$ It helps in achieving a highly polished, mineral rich surface, elongating the amount of time taken for colonization by mutans streptococci on the tooth surface. ${ }^{7}$ However, since hydrochloric acid is used in the procedure, it may create microscopic roughness and microporosities on the surface of the enamel.

The role of mutans streptococci in the etiology of caries has been well established since the 1970s. Their survival in the oral environment is highly dependent on their ability to adhere to the tooth surface. ${ }^{8}$ The use of hydrochloric acid in microabrasion may provide the retentive layer required by caries inducing mutans streptococci.

The microscopic loss of tooth structure resulting from this procedure is reversible, and remineralization may be attempted. The process of remineralization owes its 
simplicity to the fact that it requires no growth factor and soft-tissue biological process in order to be effective. Hence in this study, we used two different remineralizing pastes on microabraded teeth after which microhardness was evaluated.

\section{MATERIALS AND METHODS}

- Ten freshly extracted human anterior teeth

- Slurry of $11 \% \mathrm{HCl}$ and fine powdered pumice.

- GC tooth mousse and tooth mousse plus

- Artificial saliva

- Micro motor handpiece

- Rubber cup

- Vicker's Microhardness Tester, Reichert Austria Make, Sl. no. 363798.

Ten freshly extracted maxillary central incisors which had no carious lesion and no restorations were chosen for this study. Eroded teeth, or teeth with visible defects, microcracks or visible stains on the facial surface were discarded. The teeth were thoroughly cleaned off its debris and soft-tissue using an ultrasonic scaler.

Each tooth was divided into four equal parts by nail paint and four groups were made on each tooth are as follows:

- Group A: Consisted of that part in which no preparation was done and which acted as a control group.

- Group B: Consisted of that parts of teeth in which only microabrasion was done.

- Group C: Consisted of the part in which $10 \%$ casein phosphopeptide-amorphous calcium phosphate (CPP-ACP) was applied after microabrasion.

- Group D: Consisted of the part in which 10\% CPPACPF was applied after microabrasion.

The application of both CPP-ACP and CPP-ACPF was done for a period of thirty days once daily for 3 minutes. Artificial saliva was the storage medium used for the samples for 30 days.

\section{Microabrasion Procedure}

Eleven percent $\mathrm{HCl}$ and fine powdered pumice was used to prepare an abrasive slurry. A rotating rubber up was used to apply the slurry to the labial surface of the tooth.

A total of $20 \mathrm{gm}$ of pressure was used and 10 second applications were carried out. After each application the slurry was rinsed away.

Application of CPP-ACP and CPP-ACPF was done directly with a clean finger, on the labial surface of the tooth, smeared over the surface for 3 minutes.

\section{Microhardness}

Microhardness was evaluated using the Vicker's Microhardness Tester, Reichert Austria Make, Sl. no. 363798 with a Vickers diamond indenter and scaled microscope. The load used was $100 \mathrm{gm}$ and was applied to the surface of the specimens for 15 seconds. Five indentations were equally placed over a circle of $1 \mathrm{~mm}$ diameter at the middle third of the specimens. The diagonal length of the indentations was measured by scaled microscope and Vickers values converted into microhardness values. Microhardness $(\mathrm{MH})$ was obtained using the following equation: hardness value $(\mathrm{HV})=1.854 \mathrm{P} / \mathrm{d}$ where $\mathrm{HV}$ is the Vicker's hardness in $\mathrm{Kgf} / \mathrm{mm}^{2}$ (Mpa), $\mathrm{P}$ is the load in $\mathrm{Kgf}$ and $\mathrm{d}$ is the length of diagonal in $\mathrm{mm}$.

\section{RESULTS}

Mean and standard deviation were estimated from the sample for each group (Graph 1). The pooled standard deviation was used to calculate the intervals which were subsequently plotted (Graph 2). All groups were normally distributed. Bartlett's method was used to test for equal variances as this method is accurate for normal data only. The equality of variances was confirmed.

Since data from all groups follow normal distribution and having same variance analysis of variance (ANOVA) was performed to confirm equality of the means of groups. The null hypothesis stated was that all the means are equal for all the groups. Equal variances were assumed for the analysis. The null hypothesis was rejected as at least one group's mean was different.

\section{DISCUSSION}

The enamel surface structure is complex to say the least. A hydration shell in the form of a layer of tightly bound

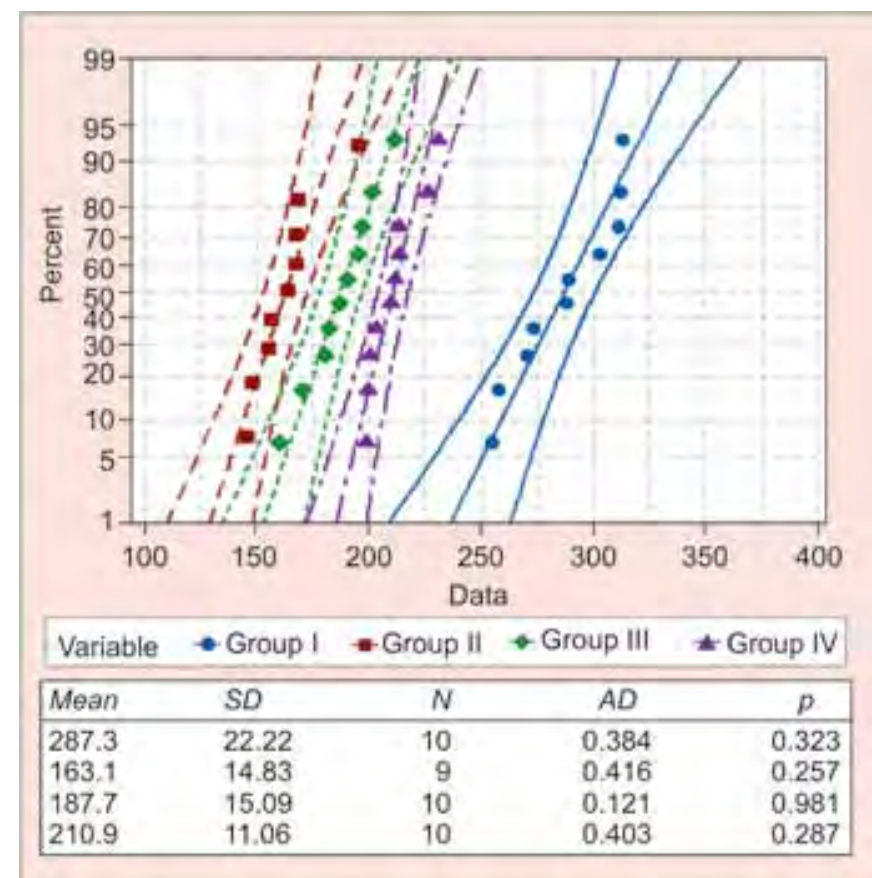

Graph 1: Probability plot of all groups (I to IV) (Normal-95\% Cl) 


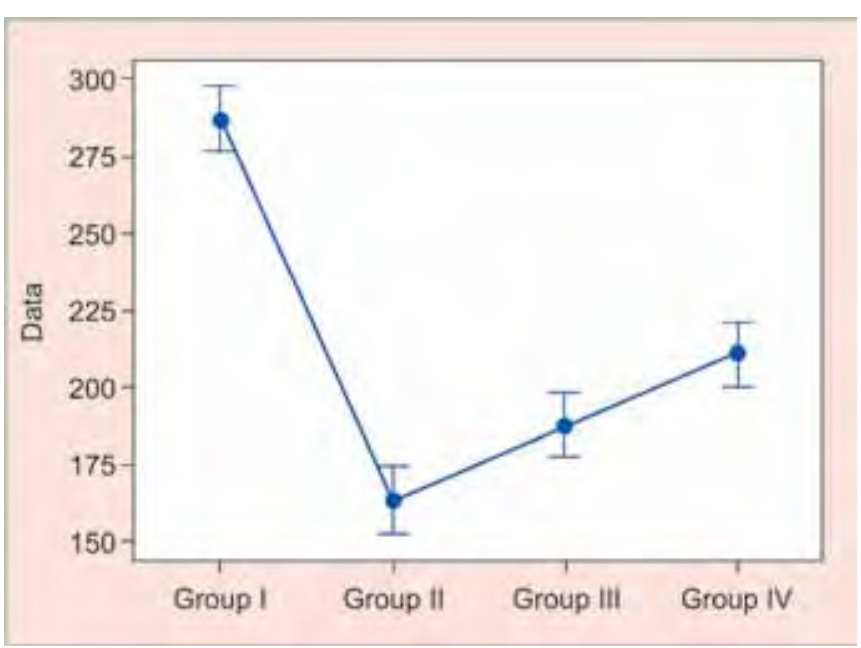

Graph 2: Interval plot of all groups (I to IV) (95\% Cl for the mean) Note: The pooled standard deviation was used to calculate the intervals

water surrounds each crystal of hydroxyapatite. ${ }^{9}$ This formation depicts that the crystal is electrically charged and can therefore attractions that are able to play a part in remineralization. ${ }^{10}$

Microabrasion, now a well-known procedure to repair surface defects, was believed to result in a smooth, polished, glossy surface. However, the hydrochloric acid used is capable of displacing the ions after penetration into the enamel thereby increasing the level of porosity and resulting in further demineralization. Interestingly, the reverse is also true as the ions can return along the same pathways and facilitate remineralization.

Sometimes, the demineralization process may outpace the remineralization resulting in the development of subsurface lesions. These may be seen as white spot lesions in the enamel. ${ }^{11}$ Evaluation of changes in the surface of enamel are highly relevant as it is this area that plays a key role in caries progression. Microhardness is a suitable technique to evaluate a microcrystalline, non-homogeneous structure like enamel. Apart from its simplicity, this test is of key importance as there has been a variety of literature describing the cause-and-effect relationship between enamel microhardness and mineral loss in caries lesion. ${ }^{11-16}$

The results of this study showed there was a significant difference in the microhardness levels of microabraded teeth treated with both the remineralizing agents. This may be due to the ability of CPP-ACP and CPP-ACPF to bind calcium and phosphate ions and stabilise amorphous calcium phosphate in metastable solution. ${ }^{17}$ Once the CPP-ACP comes in contact with the oral environment, it binds to biofilms, plaque, bacteria, hydroxyapatite and soft-tissue, localizing bioavailable calcium and phosphate ions, intrinsically remaining supersaturated with respect toenamel, resulting in reduced demineralization and increased remineralization. ${ }^{18-25}$ Casein phosphopeptide-amorphous calcium phosphate with fluoride showed higher microhardness values implying a stronger remineralization potential as compared to its counterpart. Thisis in agreement with thestudy doneby Reynoldsetal ${ }^{26}$ as wellasseveralotherstudies. ${ }^{11-16,28}$ Casein phosphopeptide-amorphous calcium phosphate with fluoride contains fluoride which allows for the formation of fluorhydroxyapatite which is more resistant to demineralization as compared to hydroxyapatite. Penetration of ions into the depth of the lesion is limited by the process of remineralization. The rapid deposition of fluorapatite allows for the formation of a firm surface layer, which is more resistant to further demineralization. ${ }^{27}$

\section{CONCLUSION}

Within the limitations of this study we can conclude that: CPP-ACP and CPP-ACPF were both effective in increasing the microhardness values of microabraded teeth and can be used following the microabrasion procedure. Application of both CPP-ACP and CPP-ACPF following the microabrasion procedure rendered the teeth much harder as compared to the microabrasion procedure alone. In contrast, CPP-ACPF was more effective in improving the microhardness of the tooth as compared to CPP-ACP.

\section{REFERENCES}

1. Croll TP. Enamel Microabrasion: observations after 10 years. J Am Dent Assoc 1997;128:45-50.

2. McCloskey RJ. A Technique for removal of fluorosis stains. J Am Dent Assoc 1984;109:63-64.

3. Croll TP, Cavanaugh RR. Enamel color modification by controlled hydrochloric acid-pumice abrasion: Part 1. Technique and examples. Quintessence Int 1986;17:81-87.

4. Croll TP. Enamel microabrasion for removal of superficial dysmineralization and decalcification defects. J Am Dent Assoc 1990;120:411-415.

5. Croll TP. Textbook-enamel microabrasion. The Technique 1991;395-400.

6. Touati B, Miara P, Nathanson D. In esthetic dentistry and ceramic restorations. London: Martin Dunitz. Treatment of tooth discolouration; 1999. p. 83-116.

7. Segura A, Donly KJ, Wefel JS. The effects of microabrasion on demineralization inhibition of enamel surfaces. Quintessence Int 1997;28:463-466.

8. Waerhaug J. Presence or absence of plaque on subgingival restorations. Scand J Dent Res 1975;83:193-201.

9. Featherstone JD. Remineralisation, the natural caries repair process-the need for new approaches. Adv Dent Res 2009; 21(1):4-7. 
10. Ferreira JM, Palamara J, Phakey PP, Rachinger WA, Orams HJ. Effects of continuous-wave $\mathrm{COz}$ laser on the ultrastructure of human dental enamel. Arch Oral Biol 1989;34:551-562.

11. Ambarkova V, Goršeta K, Jankulovska M, Glavina D, Škrinjarić I. Effect of the fluoride gels and varnishes comparing to CPP-ACP complex on human enamel demineralization/remineralization. Acta stomatol Croat 2013;47:99-110.

12. Ambarkova V, Goršeta K, Glavina D, Škrinjarić I. The effect of fluoridated dentifrice formulations on enamel remineralisation and microhardness after in vitro demineralization. Acta Stomatol Croat 2011;45:159-165.

13. Lata S, Varghese NO, Varughese JM. Remineralization potential of fluoride and amorphous calcium phosphatecasein phosphopeptide on enamel lesions: an in vitro comparative evaluation. J Conserv Dent 2010;13:42-46.

14. Kusano SC, Tenuta LA, Curry AAD, Curry JA. Timing of flouride toothpaste use and enamel dentin demineralization. Braz Oral Res 2011;25:1-6.

15. Jabbarifar SE, Salavati S, Akhavan A, Khosravi K, Tavakoli N, Nilchian F. Effect of fluoridated dentifrices on surface microhardness of the enamel of deciduous teeth. Dent Res 2011;8: 113-117.

16. Vongsawan K, Surarit R, Rirattanapong P. The effect of high calcium milk and casein phosphopeptide-amorphous calcium phosphate on enamel erosion caused by cholinated water. Southeast Asian J Trop Med Public Health 2010;41:1494-1499.

17. Walsh LJ. Preventive dentistry for the general dental practitioner. Aust Dent J 2000;45:76-82.

18. Reynolds EC. Anticariogenic casein phosphopeptides. Prot Peptide Lett 1999;6:295-303.
19. Rose RK. Effects of an anticariogenic casein phosphopeptide on calcium diffusion in streptococcal model dental plaques. Arch Oral Biol 2000;45:569-575.

20. Reynolds EC. Remineralization of enamel subsurface lesions by casein phosphopeptide-stabilized calcium phosphate solutions. J Dent Res 1997;76(9):1587-1595.

21. Reynolds EC. The role of phosphopeptides in caries prevention. Dent Perspectives 1999;3:67.

22. Vashisht R, Kumar A, Srinivasan IMR, Ramchandran S. Remineralization of early enamel lesions using casein phosphopeptide amorphous calcium phosphate: an ex-vivo study. Contemp Clini Dent 2010;1:210-213.

23. Oshiro $M$, Yamaguchi $K$, Takamizawa $T$, Inage $H$, Watanabe $T$, Irokawa A, Ando S, Miyazali M. Effect of CPP-ACP paste on toothmineralization on FE-SEMstudy.JOralSci 2007;49:115-120.

24. Shirahatti RV, Ankola AV, Nagesh L, Hallikerimath S. The effects of three different pastes on enamel caries formation and lesion depth progression: an in vitro study. J Oral Health Comm Dent 2007;1:1-6.

25. Nasution AI, Zawil C. The comparison of enamel hardness between fluoride and theobromine application. Int J Contemp Dent Med Rev 2014;1-4.

26. Reynolds EC, Cai F, Cochrane NJ, Shen P, Walker GD, Morgan MV, Reynolds C. Fluoride and casein phosphopeptideamorphous calcium phosphate. J Dent Res 2008;87(4):344-348.

27. Karlinsey RL, Mackey A, Stookey GK. In vitro remineralization efficacy of $\mathrm{NaF}$ systems containing unique forms of calcium. Amer J Dent 2009;22:185-188.

28. Badr SBY, Ibrahim MA. Protective effect of three different fluorides pretreatment on artificially induced dental erosion in primary and permanent teeth. J Amer Sci 2010;6:442-450. 